J. Lake Sci.(湖泊科学), 2009, 21(1): 123-127

http://www.jlakes.org. E-mail: jlakes@niglas.ac.cn

(C2009 by Journal of Lake Sciences

\title{
铜绿微囊藻生长对培养液 $\mathrm{pH}$ 值和氮转化的影响“
}

吴 剑, 孔 倩, 杨柳燕 ${ }^{* *}$, 肖 琳, 孙 成

(污染控制与资源化研究国家重点实验室, 南京大学环境学院, 南京 210093)

摘 要: 在不同初始 $\mathrm{pH}$ 值条件下培养蓝藻水华优势种铜绿微囊藻(Microcystis aeruginosa), 研究其生长过程对培养液的 $\mathrm{pH}$ 值 和氮转化的影响. 结果表明, 处于延迟期和对数生长期的铜绿微囊藻使培养液的 $\mathrm{pH}$ 值上升, $\mathrm{pH}$ 从初始的 7.2、8.0 和 8.8 分别 上升到最大值 $10.02 、 10.34$ 和 10.94; 稳定期和衰亡期的微囊藻使培养液 $\mathrm{pH}$ 值降低. 初始 $\mathrm{pH}$ 值为 8.8 时, 最终 $\mathrm{pH}$ 降至 8.66. 在微囊藻生长过程中, 培养液中 $\mathrm{NO}_{3}{ }^{-}$含量逐渐降低, $\mathrm{NO}_{2}{ }^{-}$含量先升高再降低, 分别在 $60 \mathrm{~d}$ 和 $67 \mathrm{~d}$ 后降至零. 试验结束时, 不同 $\mathrm{pH}$ 值培养液中总氮含量比起始时分别下降了 $25.97 \%$ 、 $27.52 \%$ 和 $28.16 \%$, 说明化合态无机氮可以经过反硝化作用生成氮气而 溢出培养液, 因此, 较大密度水华水体中存在反硝化的脱氮过程,

关键词: 铜绿微囊藻; $\mathrm{pH}$ 值; 氮转化

\section{Effect of the growth of Microcystis aeruginosa on the $\mathrm{pH}$ value and the nitrogen transformation in the medium}

\author{
WU Jian, KONG Qian, YANG Liuyan, XIAO Lin \& SUN Cheng \\ (State Key Laboratory of Pollution Control and Resource Reuse, School of the Environment, Nanjing University, Nanjing 210093, \\ P.R.China)
}

\begin{abstract}
Microcystis aeruginosa, dominance specie in the cyanobacterial bloom, was cultured under the different initial $\mathrm{pH}$ values in order to study the effect of the growth of $M$. aeruginosa on the $\mathrm{pH}$ value and the nitrogen transformation in the medium. The results showed that the $\mathrm{pH}$ value rose in the lag phase and exponential phase of M. aeruginosa, and the maximum $\mathrm{pH}$ values rose from 7.2, 8.0 and 8.8 to $10.02,10.34$ and 10.94 respectively, then decreased in the stationary phase and the decline phase of $M$. aeruginosa. While initial $\mathrm{pH}$ value was 8.8 , it decreased to 8.66 at the end of the experiment. $\mathrm{NO}_{3}{ }^{-}$concentration decreased and $\mathrm{NO}_{2}{ }^{-}$ concentration rose earlier then decreased later in the medium during the growth period of M. aeruginosa. Both the concentrations of $\mathrm{NO}_{3}{ }^{-}$and $\mathrm{NO}_{2}{ }^{-}$decreased next to zero in the 60th and the 67th days, respectively. Compared with the initial total nitrogen content, the final total nitrogen contents decreased $25.97 \%, 27.52 \%$ and $28.16 \%$ under different initial $\mathrm{pH}$ values, respectively. The nitrogenous compound was transformed to $\mathrm{N}_{2}$ through denitrification. Thus, there is distinct decrease of nitrogenous compound by denitrification in M. aeruginosa bloom.
\end{abstract}

Keywords: Microcystis aeruginosa; $\mathrm{pH}$ value; nitrogen transformation

由水体富营养化引起的以铜绿微囊藻 (Microcystis aeruginosa) 为优势种群的水华暴发已经是国内外 公众关注的焦点. 特别是 2007 年太湖饮用水危机事件以后, 蓝藻水华的生态学危害被高度重视, 铜绿微 囊藻水华的暴发首先是与外源性营养盐有关, 其中氮是主要生源要素之一. 在蓝藻水华暴发时, 水体中 $\mathrm{pH}$ 值会快速上升，同时每天 $\mathrm{pH}$ 值波动也较大 ${ }^{[1-2]}$, 但水华衰亡过程中水体 $\mathrm{pH}$ 值的变化还未见报道. 到 目前为止, 对蓝藻水华生态学的研究主要集中于氮、磷元素对蓝藻生长和繁殖的影响上 ${ }^{[3-4]}$, 而在蓝藻水

* 国家重点基础研究发展计划(2008CB418102)和国家科技支撑计划(2006BAJ08B01-02)联合资助. 2008-05-09 收稿; 2008-08-04 收修改稿. 吴剑, 男, 博士研究生.

** 通讯作者; E-mail: yangly@nju.edu.cn. 
华生命周期中蓝藻对水体中氮元素的反作用过程研究相对较少. 因此, 通过研究不同初始 $\mathrm{pH}$ 值条件下铜 绿微囊藻生长对培养液 $\mathrm{pH}$ 值和氮转化的影响, 探索蓝藻水华对湖泊水生态系统氮素的影响, 为评估湖泊 水华生态影响和蓝藻水华的控制提供基础数据.

\section{1 材料与方法}

\section{1 试验材料}

铜绿微囊藻(Microcystis aeruginosa) 由中国科学院武汉水生生物研究所提供, 用改良的 MA培养基培 养 ${ }^{[5]}$. 培养条件为温度 $25^{\circ} \mathrm{C}$, 光暗比 $12 \mathrm{~h} / 12 \mathrm{~h}$ 和光照度 $22001 \mathrm{x}$.

\section{2 试验方法}

1.2.1 试验设置 试验所用 $\mathrm{MA}$ 培养基中, 用 $\mathrm{NaH}_{2} \mathrm{PO}_{4}$ 代替甘油磷酸钠, 设置初始 $\mathrm{pH}$ 值分别为 $7.2 、 8.0$ 和 8.8 .

1.2.2 接种及培养 在 2007 年 3-5 月, 将处于对数生长末期铜绿微囊藻经离心 ( $4000 \mathrm{r} / \mathrm{min}, 15 \mathrm{~min})$, 洗涤后 接人试验培养液中, 初始藻密度约 $2 \times 10^{6} \mathrm{cell} / \mathrm{s} / \mathrm{ml}$. 光暗比 $12 \mathrm{~h} / 12 \mathrm{~h}$, 光照度 $2200 \mathrm{~lx}, 25^{\circ} \mathrm{C}$ 培养. 所有试验组 三个平行.

1.2 .3 测定指标及方法 (1)用 HI8424 精密 $\mathrm{pH}$ 计测定培养液 $\mathrm{pH}$ 值. (2)铜绿微囊藻生长曲线的测定: 测铜 绿微囊藻培养液的光密度 $\mathrm{OD}_{460}$ 和用血小球计数板计数铜绿微囊藻的浓度, 作光密度与细胞数量相关性 曲线, 然后通过测定微囊藻培养液的光密度, 再换算得到藻细胞数. (3)在试验开始和结束时, 直接用碱性 过硫酸钾消解含藻培养液, 然后采用过硫酸钾氧化紫外分光光度法测定 $1 \mathrm{ml}$ 含藻培养液中总氮含量. (4) 取藻液 $4 \mathrm{ml}, 7000 \mathrm{r} / \mathrm{min}$ 离心 $15 \mathrm{~min}$ 后取上清液, 分别采用紫外分光光度法和 $\mathrm{N}-$-(1-菜基)-乙二胺光度法测 定上清液中 $\mathrm{NO}_{3}$ - 和 $\mathrm{NO}_{2}{ }^{-}$的含量.

\section{2 试验结果及讨论}

\section{1 不同初始 $\mathrm{pH}$ 值对铜绿微囊藻生长和培养液 $\mathrm{pH}$ 变化的影响}

不同初始 $\mathrm{pH}$ 值条件下, 铜绿微囊藻的生长曲线(图 1)说明, 在开始 $61 \mathrm{~d}$ 内, 铜绿微囊藻密度都随着 $\mathrm{pH}$ 值升高而增加. 初始 $\mathrm{pH}$ 值为 8.8 时, 铜绿微囊藻生长速率最快, $\mathrm{pH}$ 值为 7.2 和 8.0 时生长曲线相似, 且 较 $\mathrm{pH}$ 值为 8.8 时晚进人对数生长期. 第 $61 \mathrm{~d}$ 时各试验组藻密度几乎相同, 之后初始 $\mathrm{pH}$ 值为 7.2 时藻密度 较其它稍高. 因此, 湖泊水体高 $\mathrm{pH}$ 值可以促进蓝藻优势种微囊藻的生长, 有利于太湖、巢湖等高 $\mathrm{pH}$ 值 湖泊微囊藻水华的暴发.

在不同初始 $\mathrm{pH}$ 值条件下，培养液中 $\mathrm{pH}$ 值随时间都呈现先上升后下降的趋势(图 2). 在初始 $\mathrm{pH}$ 值为 $7.2 、 8.0 、 8.8$ 时, $\mathrm{pH}$ 值分别上升到最高的 $10.02 、 10.34$ 和 10.94 , 分别升高了 $2.87 、 2.39$ 和 2.35 单位, 达 到最大 $\mathrm{pH}$ 值所需时间分别为 $81 、 61$ 和 $48 \mathrm{~d}$. 初始 $\mathrm{pH}$ 值为 8.8 的情况下, 试验结束时培养液 $\mathrm{pH}$ 值又降 至 8.66. 铜绿微囊藻在对数生长期时光合作用强烈, 其吸收培养液中 $\mathrm{CO}_{2}$ 和 $\mathrm{HCO}_{3}^{-}$进行光合作用使培养 基 $\mathrm{pH}$ 值升高. 铜绿微囊藻在稳定期和衰亡期光合作用减弱而呼吸作用增强，呼吸作用产生的 $\mathrm{CO}_{2}$ 溶于水 使培养基 $\mathrm{pH}$ 值下降.

已有试验研究表明, 水体高 $\mathrm{pH}$ 值有利于铜绿微囊藻的生长 ${ }^{[3,7]}$, 本试验中无论铜绿微囊藻处于对数 生长期还是稳定衰亡期均呈现此现象. 微囊藻进入稳定期后, 短时间内各试验组藻密度虽然无明显降低, 但微囊藻的颜色由蓝绿色逐渐变为黄绿色甚至黄色, 且变黄的先后顺序与培养基中 $\mathrm{pH}$ 值开始降低的顺 序相同.

比较图 1 和图 2 可以发现, 培养液高 $\mathrm{pH}$ 值有利于微囊藻生长, 微囊藻生长又使水体 $\mathrm{pH}$ 上升, 如此 形成一个良性循环, 使微囊藻暴发式生长. 当 $\mathrm{pH}$ 值从高位下降时, 微囊藻的生长也减弱, 而初始 $\mathrm{pH}$ 值较 低时培养液 $\mathrm{pH}$ 值上升迟缓, 微囊藻继续处于生长的状态, 因此, 水体中 $\mathrm{pH}$ 值变化和微囊藻密度的变化 是它们交互作用的结果, 为互为因果关系. 

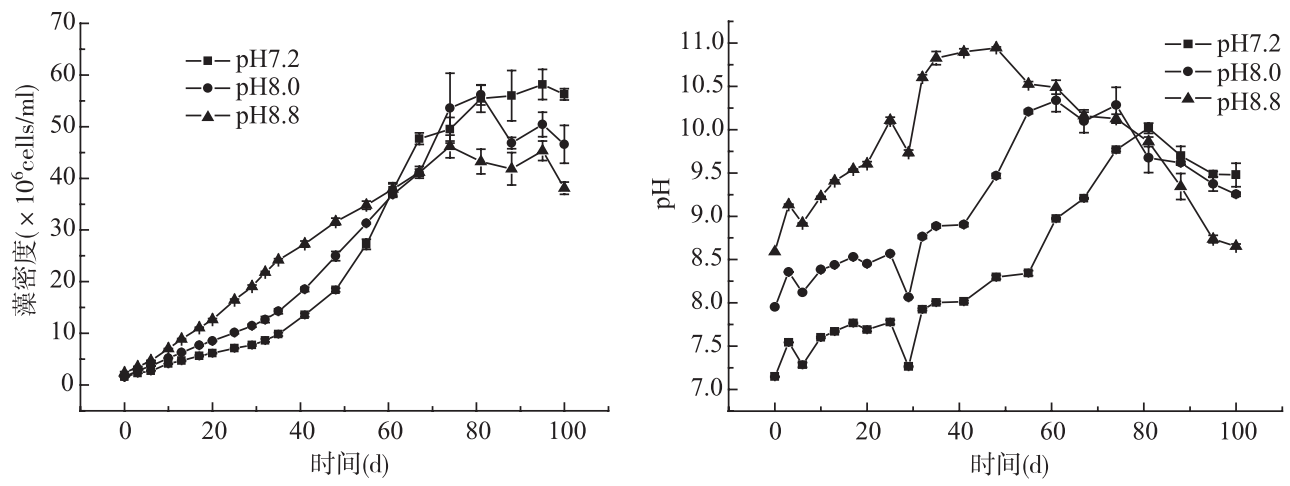

图 1 不同初始 $\mathrm{pH}$ 值条件下铜绿微囊藻密度变化 图 2 不同初始 $\mathrm{pH}$ 值时培养液 $\mathrm{pH}$ 值变化过程

Fig.1 Variation of the density of $M$. aeruginosa under different initial $\mathrm{pH}$

Fig.2 Variation of $\mathrm{pH}$ value in medium under different initial $\mathrm{pH}$

\section{2 不同初始 $\mathrm{pH}$ 值时培养液中氮转化}

2.2.1 不同初始 $\mathrm{pH}$ 值条件下, 培养液中 $\mathrm{NO}_{3}^{-}$和 $\mathrm{NO}_{2}{ }^{-}$浓度的变化 初始 $\mathrm{pH}$ 值为 7.2 和 8.0 条件下, 培养液 中 $\mathrm{NO}_{3}$ 浓度基本一直呈下降趋势. 不同初始 $\mathrm{pH}$ 值条件下, $\mathrm{NO}_{3}{ }^{-}$含量在 $61 \mathrm{~d}$ 后都下降到零(图 3). 培养液中 $\mathrm{NO}_{2}$-含量都呈先缓慢上升后急剧下降的趋势, 最大值分别为 $2.055 、 2.302$ 和 $1.152 \mathrm{mg} / \mathrm{L}$, 达到最大值的时 间分别为 $55 、 41$ 和 $41 \mathrm{~d}$. 初始 $\mathrm{pH}$ 为 8.0 条件下，培养基中 $\mathrm{NO}_{2}$ 浓度达到最大. 在 $\mathrm{NO}_{2}$-浓度上升过程中，初 始 $\mathrm{pH} 8.0$ 时, $\mathrm{NO}_{2}{ }^{-}$上升速率最大, 8.8 时次之, 7.2 时最小. 初始 $\mathrm{pH}$ 值 8.8 时, $\mathrm{NO}_{2}{ }^{-}$浓度从最大值下降到零所 需时间最短, 而初始 $\mathrm{pH}$ 值 8.0 时所需时间最长(图 4).

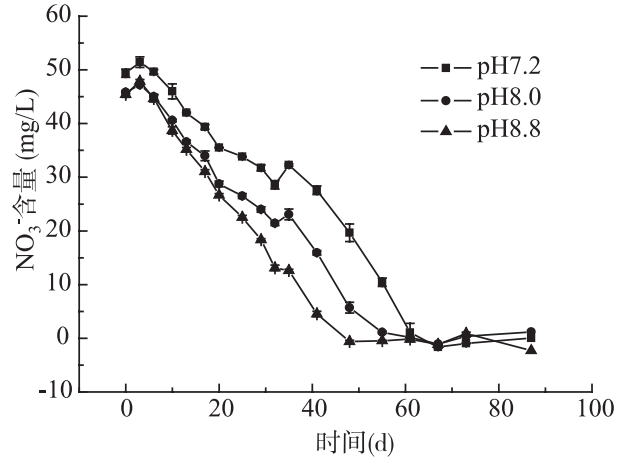

图 3 不同初始 $\mathrm{pH}$ 值条件下培养液中 $\mathrm{NO}_{3}{ }^{-}$含量变化

Fig.3 Variation of $\mathrm{NO}_{3}{ }^{-}$concentration in medium under different initial $\mathrm{pH}$

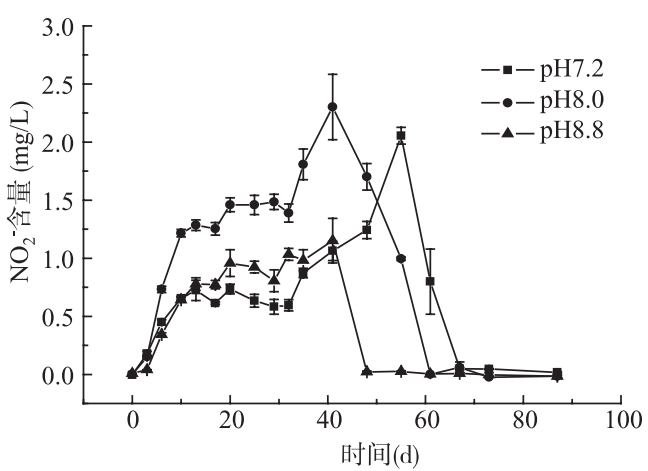

图 4 不同初始 $\mathrm{pH}$ 值条件下培养液中 $\mathrm{NO}_{2}{ }^{-}$含量变化

Fig.4 Variation of $\mathrm{NO}_{2}{ }^{-}$concentration in medium under different initial $\mathrm{pH}$

在培养液中 $\mathrm{NO}_{3}^{-}$浓度不断降低, $\mathrm{NO}_{2}{ }^{-}$含量先升高后降低至零, 这是由于培养液存在反硝化过程. 铜 绿微囊藻在光照条件下光合作用产氧, 黑暗条件下呼吸作用耗氧从而造成氧化还原电位较低, 有利于自 养反硝化作用的进行. 本试验中, 初始 $\mathrm{pH}$ 值为 8.0 条件下, $\mathrm{NO}_{2}$ 浓度增加的最快, 下降的最慢, 这说明反 硝化过程中，初始 $\mathrm{pH}$ 值为 8.0 时较有利于反硝化反应形成 $\mathrm{NO}_{2}^{-}$，而不利于 $\mathrm{NO}_{2}{ }^{-}$转化为氮气.

同时, 比较图 1 和图 4 发现, 微囊藻的生长与培养液中氮浓度有关. 当培养液中氮下降到零后, 微囊 藻停止生长. 蓝藻体内含有特殊的藻蓝蛋白和别藻蓝蛋白, 这两种蛋白加上叶绿素蛋白而使蓝藻藻体呈 现蓝绿色 ${ }^{[8]}$. 本试验后期, 培养基中 $\mathrm{NO}_{3}{ }^{-}$和 $\mathrm{NO}_{2}$ 浓度都下降, 总氮浓度很低. 氮限制可能会在翻译水平 
上通过降低细胞内部氨基酸库浓度影响蛋白质的合成 ${ }^{[9]}$. 蓝藻和微藻的藻胆蛋白在氮限制阶段可以作为氮 的䛎藏化合物 ${ }^{[10-12]}$, 红藻也是如此 ${ }^{[12]}$. 对 Chroococcidiopsis sp.的氮胁迫研究表明 ${ }^{[13]}$, 在 N/4 BG-11(62.5 $\mu \mathrm{g}$ $/ \mathrm{ml}$ )和 BG- $11_{0}$ (无氮)两种氮浓度条件下, Chroococcidiopsis 分别培养 3 个月和 1 个月后出现萎黄现象. 氮 限制对其它藻类如单细胞红藻 Galdieria sulphuraria $074 \mathrm{G}$ 中藻青蛋白的影响同样存在 ${ }^{[12]}$, 碳和氮的可利 用性及光强都影响 G. sulphuraria 中藻青蛋白的合成. 但已有研究表明, 氮重新充足 $15 \mathrm{~d}$ 后 N/4 限制性和 氮饥饿培养 Chroococcidiopsis4 个月后, 细胞内藻青蛋白含量又分别恢复到初始量的 $92 \%$ 和 $80 \%$, 叶绿素 含量恢复到初始量的 $88 \%$ 和 $75 \%{ }^{[13]}$. 因此, 本试验后期培养液中氮限制导致藻细胞内叶绿素和藻青蛋白 含量降低, 从而藻细胞从蓝绿色变为黄绿甚至黄色, 使微囊藻转人衰亡阶段.

2.2.2 不同初始 $\mathrm{pH}$ 值条件下, 含藻培养液中总氮浓度变化 试验结束时含藻培养液中总氮浓度如图 5 所示. 在不同初始 $\mathrm{pH}$ 值条件下, 培养液中总氮含量都会降低. 在初始 $\mathrm{pH}$ 值分别为 $7.2 、 8.0$ 和 8.8 时, 含藻培养 液中总氮浓度从 $0.08394 \mathrm{mg} / \mathrm{ml}$ 分别下降到 $0.06214 、 0.06084$ 和 $0.06030 \mathrm{mg} / \mathrm{ml}$, 相应减少了 $25.97 \% 、 27.52 \%$ 和 $28.16 \%$, 这说明试验过程中一部分硝态氮经过反硝化作用转化成了氮气并溢出体系外, 从而使培养液 中氮营养盐含量得到一定程度的削减.

本试验后期, 培养液中藻密度较大加上氮营养盐限制导致微囊藻细胞光合作用减弱, 氧气产生量减 少，从而培养液中氧化还原电位较低 ${ }^{[14]}$, 这有利于铜绿微囊藻利用 $\mathrm{NO}_{3}{ }^{-}$为呼吸作用的最终电子受体把硝 酸盐还原成亚硝酸盐甚至氮气过程, 进行自养脱氮作用. 因此, 微囊藻水华的存在可以大大改变湖泊水 体氮循环的途径, 有利减少湖泊水体中氮数量, 从而对水生态系统产生影响 ${ }^{[15]}$.

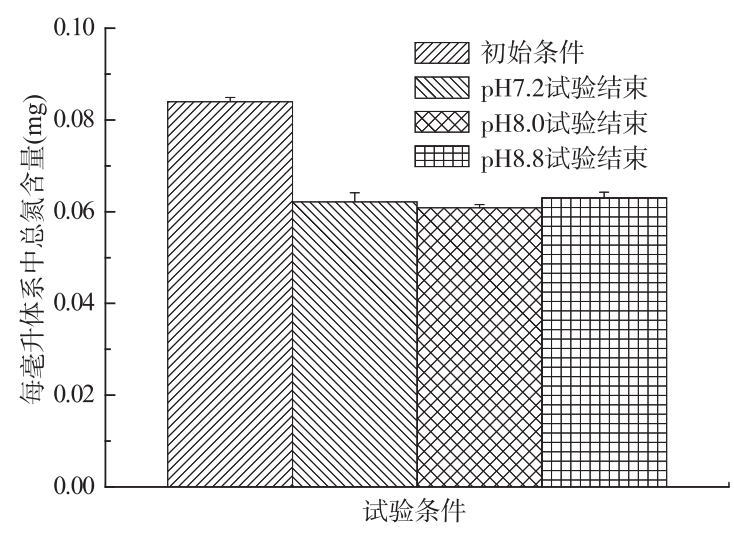

图 5 不同初始 $\mathrm{pH}$ 值时含藻体系中总氮含量变化

Fig.5 Variation of total nitrogen content in medium containing M. aeruginosa under different initial $\mathrm{pH}$

\section{3 结论}

本试验研究了不同初始 $\mathrm{pH}$ 值时蓝藻水华优势种铜绿微囊藻的生长对培养液中 $\mathrm{pH}$ 值和氮转化的影响. 在铜绿微囊藻处于延迟期和对数生长期时培养液 $\mathrm{pH}$ 值升高, 而在其稳定期和衰亡期时培养液 $\mathrm{pH}$ 值下降, 初始 $\mathrm{pH}$ 值为 8.8 时培养液 $\mathrm{pH}$ 值最高升到 10.94 , 到试验结束时再下降到 8.66 , 接近其初始值, 表明在水 华暴发和衰亡过程中, 培养液中 $\mathrm{pH}$ 值存在升高和回落的过程.

在微囊藻的生长过程中, 存在水体中总氮下降的现象. 本试验后期培养液中无机氮含量几乎降到零, 使铜绿微囊藻处于氮胁迫状态, 从而使微囊藻转人衰亡阶段. 同时使 $\mathrm{NO}_{3}$ 还原为 $\mathrm{NO}_{2}{ }^{-}$甚至 $\mathrm{N}_{2}$, 生成的氮 气溢出体系外, 这说明在蓝藻聚集形成水华过程中存在着有效自养脱氮作用, 从而使湖泊水体形成一种 自我修复的机制来减低湖泊水体中氮含量.

\section{4 参考文献}

[1] 王志红, 崔福义, 安 全等. $\mathrm{pH}$ 与水库水富营养化进程相关性研究. 给水排水, 2004, 30(5): 37-41. 
[2] Shapiro J. Current beliefs regarding dominance by blue-greens: The case for the importance of $\mathrm{CO}_{2}$ and $\mathrm{pH}$. International Vereinigung fuer Theoretische und Angewandte Limnologie, 1990, 24(1): 38-54.

[3] Ha Kyong, Cho Eun-Ah, Kim Hyun-Woo et al. Microcystis bloom formation in the lower Nakdong River, South Korea: importance of hydrodynamics and nutrient loading. Marine and Freshwater Research, 1999, 50(1): 89-94.

[4] JIN Xiangcan, LI Zhaochun, ZHENG Shuofang et al. Studies on the growth characteristics of Microcystis aeruginosa. Research of Environmental Sciences, 2004, 17: 52-54, 61.

[5] 邹 迪, 肖 琳, 杨柳燕等. 不同氮磷比对铜绿微囊藻及附生假单胞菌磷代谢的影响. 环境化学, 2005, 24(6): 647-650.

[6] Shapiro J. Blue-green dominance in lakes: The role and management significance of $\mathrm{pH}$ and $\mathrm{CO}_{2}$. International Revue der Gesamten Hydrobiology, 1984, 69(6): 765-780.

[7] Don L Tucker, Louis A Sherman. Analysis of chlorophyll-protein complexes from the cyanobacterium Cyanothece sp. ATCC 51142 by non-denaturing gel electrophoresis. Biochimica et Biophysica Acta, 2000, 1468: 150-160.

[8] Flynn KJ, Dickson DMJ, Al-Amoudi OA. The ratio of glutamine: glutamate in microalgae: a biomarker for nitrogen status for use at natural cell densities. Journal of Plankton Research, 1989, 11: 165-170.

[9] Boussiba S, Richmond A. C-phycocyanin as a storage protein in the blue-green alga Spirulina platensis. Arch Microbiol, 1980, 125: $143-147$.

[10] Levy I. Gantt E. Development of photosynthetic activity in Porphyridium purpureun (Rhodophyta) following nitrogen starvation. J Phycol, 1990, 26: 62-68.

[11] Lewitus AJ, Carbon DA. Relative effects of nitrogen or phosphorus depletion and light intensity on the pigmentation, chemical composition, and volume of Pyrenomonas salina(Cryptophyceae). Mar Ecolo Prog Ser, 1990, 61: 171-181.

[12] Jenni KS, Marilyn GW, Niels TE. Accumulation of phycocyanin in heterotrophic and mixotrophic cultures of the acidophilic red alga Galdieria sulphuraria. Enzyme and Microbial Technology, 2006, 38: 168-175.

[13] Daniela Billi, Maria Grilli Caiola. Effects of nitrogen limitation and starvation on Chroococcidiopsis sp. (Chroococcales). New Phytol, 1996, 133: 563-571.

[14] 张 民, 孔繁翔, 史小丽等. 铜绿微囊藻在竞争生长条件下对氧化还原电位降低的响应. 湖泊科学, 2007, 19(2): 118-124.

[15] 曾 巾, 杨柳燕, 肖 琳等. 湖泊氮素生物地球化学循环及微生物的作用. 湖泊科学, 2007, 19(4): 382-389. 